\section{VLBW: Wann mit dem Abpumpen von Muttermilch beginnen?}

Parker MG et al. Timing of first milk expression to maximize breastfeeding continuation among mothers of very low-birth-weight infants. Obstet Gynecol 2019; 133: 1208-1215

Neugeborene mit einem sehr niedrigen Geburtsgewicht (,very low birth Weight“, VLBW) profitieren in unterschiedlicher Weise von Muttermilch. Diese wirkt beispielsweise einer nekrotisierenden Enterokolitis entgegen und unterstützt die spätere Entwicklung während der Kindheit. M.G. Parker et al. haben bei Müttern von VLBW-Neugeborenen untersucht, inwieweit der Zeitpunkt des 1. Milchabpumpens die Dauer der Bereitstellung von Muttermilch beeinflusst.

Die Analyse basierte auf Daten des „Neonatal Quality Improvement Collaborative of Massachusetts“-Projekts. Dieses fand zwischen Januar 2015 und Dezember 2017 an 9 Neugeborenenintensivstationen in Massachusetts/USA statt. Berücksichtigt wurden 1157 Mütter mit ihren VLBW-Neugeborenen (Geburtsgewicht $1500 \mathrm{~g}$ oder darunter). Die Autoren legten eine Zeitspanne für die 1. Gewinnung von Muttermilch fest, die mit der höchsten Wahrscheinlichkeit für eine Bereitstellung von

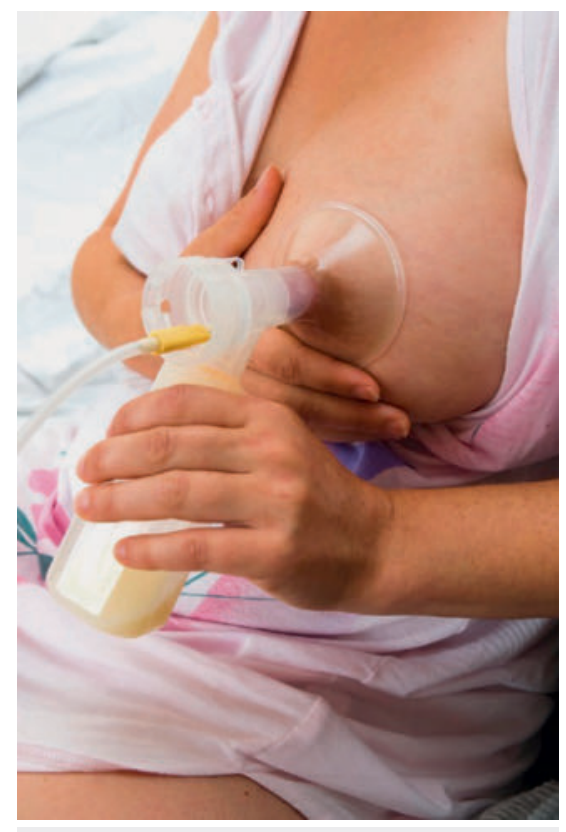

Um bei sehr unreifen Frühgeborenen eine ausreichende Nährstoffzuführung sicher zu stellen, wird ein Teil der Muttermilch abgepumpt, mit zusätzlichen Nährstoffen angereichert und per Flasche oder Magensonde gefüttert. Ob ein frühzeitiges Abpumpen die Dauer der Bereitstellung von Muttermilch beeinflusst, untersuchten Parker et al. Symbolbild. Quelle: spunk74, Fotolia.com

Muttermilch zum Zeitpunkt der Entlassung von der Intensivstation oder einer Verlegung in Zusammenhang stand („Cut Point": 8 Stunden nach der Geburt). Es wurde untersucht, wie sich ein Beginn des Milchabpumpens vor und nach diesem Zeitpunkt auf die Dauer der späteren Milchbereitstellung auswirkte. Dies geschah nach Adjustierung für das Gestationsalter, das Geburtsgewicht sowie die Rasse bzw. Ethnie der Mutter.

\section{Ergebnisse}

Bei 68\% der Mütter erfolgte die erstmalige Gewinnung von Muttermilch während der ersten 8 Stunden nach der Geburt und bei 32\% nach 9-24 Stunden. An Tag 7 erhielten $90 \%$ der Neugeborenen irgendeine Art von Muttermilch, an Tag 28 86\% und zum Zeitpunkt der Entlassung von der Intensivstation oder der Verlegung 65\%. Die Autoren ermittelten einen Zusammenhang zwischen dem Beginn des Milchabpumpens nach 9-24 Stunden und einer 
geringeren Wahrscheinlichkeit für eine Bereitstellung von Muttermilch an Tag 7 (adjustierte Odds Ratio [aOR] 0,39) und bei der Entlassung oder Verlegung (aOR 0,45) gegenüber einer erstmaligen Milchgewinnung innerhalb von 8 Stunden nach der Geburt. Die Ergebnisse hinsichtlich einer alleinigen Nutzung von Muttermilch waren vergleichbar. Im Vergleich zu Müttern, die während eines Zeitfensters von 8 Stunden nach der Geburt mit dem Abpumpen begonnen hatten, endete die Versorgung mit Muttermilch während der Hospitalisierung im Fall eines Abpumpbeginns nach 9-24 Stunden (adjustierte Hazard Ratio 1,64) früher.

FAZIT

Ein Abpumpbeginn während des ersten 8 Stunden nach der Geburt führte im Fall von Frauen mit VLBW-Neugeborenen im Vergleich zu einem späteren Beginn zu einer dauerhafteren Bereitstellung von Muttermilch. Die Autoren empfehlen die Durchführung von randomisiert-kontrollierten Studien, um den kausalen Zusammenhang zwischen dem Startzeitpunkt des Milchabpumpens und der Dauer der Milchversorgung genauer zu untersuchen.

Dr. Frank Lichert, Weilburg 